\title{
Protocolization, Standardization and the Need for Adaptive Expertise in our Medical Systems
}

\author{
William B. Cutrer ${ }^{1} \cdot$ Jesse M. Ehrenfeld $^{1}$
}

Published online: 9 November 2017

(C) Springer Science+Business Media, LLC 2017

Increasingly, protocols are being used to drive the consistent application of standardized approaches to the delivery of health care. The efficient and effective use of known solutions demonstrates routine expertise. Standardization and the increased adoption of clinical guidelines have been cited as providing helpful guidance to clinicians and medical systems alike. In many circumstances, standardization can improve the quality of clinical decision making - especially when a healthcare worker is unsure of what do when facing a given set of circumstances [1]. It has been noted that "much of an experienced practioner's daily practice has less to do with solving problems than remembering solutions." Protocols and standardization are ideal in such scenarios to ensure effective and efficient solution application.

However, clinical guidelines are not a foolproof solution to medical decision making, and clinicians are increasingly confronted with new challenges without standardized solutions [2]. Protocols may be wrong or provide incorrect guidance for an individual patient. This may be driven by inappropriate generalization of a piece of evidence generated from a narrowly defined population. Practitioners may also be led to the wrong decision by only taking into account the needs of a specific patient, while ignoring the context of the larger healthcare system. Both the use of flawed protocols and over

This article is part of the Topical Collection on Education \& Training

William B. Cutrer

bill.cutrer@Vanderbilt.Edu

1 Vanderbilt University School of Medicine, Nashville, TN, USA reliance on decision aids can lead to waste and the ineffective practice of medicine.

In our opinion, now more than ever we must develop adaptive expertise to combat the downsides of the standardization of the practice of medicine. Adaptive expertise uses knowledge and understanding to create or apply knowledge to solve these novel challenges [3]. Adaptive expertise recognizes that the routine approach, including protocols and guidelines, will not work in the given scenario, and reframes the problem to facilitate exploration of new ideas (learning) and/or creation of new solutions (innovation) [4]. Adaptive expertise has been described as a "product of a learned skillset, characterized by habits of mind that develop over time and with practice" [5], making it even more essential that education to foster and develop this expertise be intentionally included in training across the continuum. Differentiating situations which are appropriate for the efficient and effective application of the appropriate protocol or guideline from those situations requiring adaptation and innovation demand the development and demonstration of adaptive expertise among medical professionals.

\section{References}

1. Woolf, S.H., Grol, R., Hutchinson, A., Eccles, M., and Grimshaw, J., Clinical guidelines: Potential benefits, limitations, and harms of clinical guidelines. BMJ. 318(7182):527-530, 1999.

2. Mylopoulos, M., and Woods, N.N., When I say ... adaptive expertise. Med. Educ. 51(7):685-686, 2017. https://doi.org/10.1111/medu. 13247.

3. Cutrer, W.B., Miller, B., Pusic, M.V., Mejicano, G., Mangrulkar, R.S., Gruppen, L.D., Hawkins, R.E., Skochelak, S.E., and Moore Jr., D.E., Fostering the development of master adaptive learners: A conceptual model to guide skill acquisition in medical education. 
Acad. Med. 92(1):70-75, 2017. https://doi.org/10.1097/ACM. 0000000000001323.

4. Carbonell, K.B., Stalmeijer, R.E., Könings, K.D., Segers, M., and van Merriënboer, J.J., How experts deal with novel situations: A review of adaptive expertise. Educ. Res. Rev. 12:14-29, 2014. https://doi.org/10.1016/j.edurev.2014.03.001.
5. Mylopoulos, M., and Woods, N.N., Having our cake and eating it too: Seeking the best of both worlds in expertise research. Med. Educ. 43(5):406-413, 2009. https://doi.org/10.1111/j.1365-2923. 2009.03307.x. 